\title{
PADRONIZAÇÃO FOTOGRÁFICA E MORFOMÉTRICA NA FOTOGRAMETRIA COMPUTADORIZADA DO NARIZ ${ }^{1}$
}

\author{
Bernardo Hochman ${ }^{2}$ \\ Helton Traber de Castilho ${ }^{3}$ \\ Lydia Masako Ferreira ${ }^{4}$
}

Hochman B, Castilho HT, Ferreira LM. Padronização fotográfica e morfométrica na fotogrametria computadorizada do nariz. Acta Cir Bras [serial online] 2002 Jul-Ago;17(4). Disponível em URL: http://www.scielo.br/acb.

RESUMO - Objetivo: Desenvolver uma padronização fotográfica e uma técnica de análise morfométrica da parte externa do nariz para comparar de forma objetiva imagens fotográficas pré e pós-operatórias. Métodos: Foram fotografadas 11 pacientes do sexo feminino portadoras de nariz negróide com idade variando entre 19 a 45 anos, sendo 2 de cor branca, 5 de cor parda e 4 de cor negra. A técnica fotográfica foi padronizada nas posições anterior, de perfil direito e basilar. Fotografias em papel foram digitalizadas e por meio de um software gráfico comum foram realizadas as fotogrametrias. Foram padronizadas 9 medidas nasais, sendo 1 em posição anterior, 3 em perfil direito e 5 em posição basilar. Resultados: O posicionamento fotográfico do paciente entre o pré e pós-operatório foi comparável. A identificação dos pontos antropométricos e linhas escolhidas foram nítidas, a obtenção de medidas foi de fácil execução, e os valores mensurados puderam ter aproximação de ordem milesimal, tornando possível a comparação dos valores. Conclusão: Os procedimentos de padronização fotográfica e análise morfométrica propostos mostraram-se exeqüíveis, práticos e precisos para avaliar de forma objetiva resultados de rinoplastia.

DESCRITORES - Nariz. Rinoplastia. Antropometria. Fotografia. Fotogrametria.

\section{INTRODUÇÃO}

O nariz pode ser dividido para exame em duas partes: externa e interna ou anatômica ${ }^{(1)}$.

A parte externa do nariz por refletir o resultado final de uma rinoplastia é o componente mais estudado. Como não existe um consenso nos métodos de mensuração, é também o componente mais confusamente analisado, principalmente em relação à base nasal, constituída pelas asas nasais, parte móvel do septo nasal e narinas ${ }^{(2)}$.

O tratamento das características do nariz negróide, além do seu componente puramente estético, é uma das operações de modificação de caracteres raciais mais comuns. Os princípios que regem a rinoplastia de nariz negróide são a redução das narinas, o estreitamento da base nasal e o aumento do perfil.

Existe na literatura controvérsia na análise dos resultados das técnicas utilizadas em rinoplastias, principalmente em narizes negróides.

Portanto, um padrão morfométrico de avaliação da parte externa do nariz poderia ser um parâmetro confiável na comparação de resultados nas rinoplastias. Uma dificuldade existente nessa avaliação reside no fato do nariz apresentar-se com acentuadas variações anatômicas devido à grande miscigenação racial.

1. Trabalho realizado no Setor de Rinologia da Disciplina de Cirurgia Plástica do Departamento de Cirurgia da Universidade Federal de São Paulo (UNIFESP / EPM).

2. Pós-Graduando do Curso de Pós-Graduação em Cirurgia Plástica da UNIFESP / EPM.

3. Professor Adjunto e Chefe do Setor de Rinologia da Disciplina de Cirurgia Plástica do Departamento de Cirurgia da UNIFESP / EPM.

4. Professora Livre Docente, Titular e Chefe da Disciplina de Cirurgia Plástica do Departamento de Cirurgia da UNIFESP / EPM. 
Outro fator que dificultaria uma análise morfométrica numa antropometria indireta por fotografia, seria a falta de observação de critérios de padronização fotográfica entre o pré e pós-operatório.

Apesar da parte externa do nariz ser geralmente fotografada nas incidências anterior, oblíqua, perfil e basilar $^{(3)}$, as fotografias nem sempre são obtidas pelo mesmo fotógrafo, equipamento, distância e condições de luminosidade. Também é comum existir uma diferença no ângulo de tomada nas fotografias em incidência basilar, o que acarretaria falsas impressões e interpretações de resultados, e a falta de normatização no ato de fotografar colaboraria na avaliação subjetiva dos $\operatorname{resultados}^{(4)}$.

WARD (1979) ${ }^{(5)}$ estabeleceu uma padronização fotográfica para a base nasal. Porém, sugeriu que a despeito de qualquer padronização, dever-se-ia obter apenas medidas de caráter relativo para avaliar resultados, como ângulos, índices ou proporções e formato ou inclinação das narinas.

FARKAS, BRYSON, TECH e KLOTZ (1980) ${ }^{(6)}$ realizaram minucioso trabalho em 36 pacientes para validar mensurações na face obtidas a partir de fotografias convencionais (fotogrametria), nas quais pontos antropométricos estavam demarcados com tinta na pele dos pacientes. Comparou as medidas com aquelas obtidas diretamente dos mesmos pacientes (antropometria direta). Das 104 medidas faciais calculadas diretamente em cada paciente, 23 foram relativas ao nariz em posição anterior e de perfil. Dessas medidas nasais somente $12(52.2 \%)$ foram passíveis de serem mensuradas pela fotogrametria, e destas, 33,3\% foram validadas, ou seja, foram idênticas ou tinham uma diferença absoluta de apenas $1 \mathrm{~mm}$ ou 2 graus em relação às medidas obtidas de forma direta.

FARKAS, KOLAR e MUNRO (1986) ${ }^{(7)}$ difundiram o uso de pontos antropométricos para fazer estudos morfométricos das narinas. Também complementaram a distribuição de Topinard (1885) sobre os tipos de narinas segundo a inclinação dos seus eixos longitudinais, que tem sido útil para classificar etnicamente o nariz pela sua base (Figura 1).

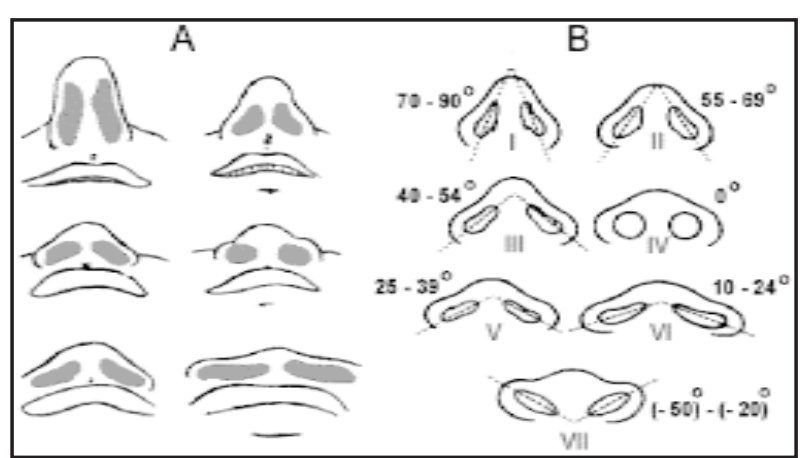

Figura 1 - Classificação da base nasal segundo a inclinação dos eixos longitudinais das narinas.

A - Topinard (1885) B - Farkas (1986)
FURNAS (1987) ${ }^{(8)}$ descreveu um método para ampliar fotografias ao tamanho natural (life-size photography) a partir da projeção da fotografia em diapositivo (slide), com uma régua graduada disposta ao lado do paciente como referência para a mensuração. O projetor era colocado sobre uma plataforma horizontal e móvel no sentido vertical, ajustada numa altura para que após refletir a imagem numa superfície espelhada a $45^{\circ} \operatorname{logo}$ à frente do mesmo, esta atinja perpendicularmente, em tamanho natural, uma mesa horizontal com papel milimetrado. Sobre este papel era disposta uma placa de acetato onde era desenhado o contorno facial e eram realizadas as mensurações nasais pré e pósoperatórias, inclusive comparando-as simultaneamente. Outro recurso sugerido para a mesma finalidade foi adaptar um xerocefalograma entre duas películas transparentes do mesmo material. $\mathrm{O}$ autor propôs também um esboço de mensuração intra-operatória por meio de réguas metálicas e osteótomos graduados.

WEBBER (1987) ${ }^{(4)}$ padronizou os períodos pósoperatórios para a obtenção de fotografias, tendo como critério a evolução das alterações cicatriciais observadas em cada parte do nariz operado.

DANIEL, HODGSON e LAMBROS (1990) ${ }^{(3)}$ enfatizaram a importância do reflexo de luz sobre as eminências no ápice nasal, uma vez que a distância entre os domus pode ser controlada por suturas afinando o ápice nasal. O sistema convencional de iluminação utilizado para fotografias comuns (não científicas) seria apropriado para realçar a aparência da pessoa e minimizar deformidades ou irregularidades. Sugeriu então padronizar um sistema quaternário de luzes, que se devidamente dispostas, realçaria estas anormalidades, além de tornar sempre simétricos os reflexos de luz no ápice nasal.

Recentemente sofisticados sistemas tecnológicos computadorizados foram especialmente desenvolvidos para realizar análises antropométricas faciais e das formas nasais externas, visando obter maior rapidez de análise e precisão das medidas.

BHATIA, VANNIER, SMITH, COMMEAN, RIOLO e YOUNG (1994) ${ }^{(9)}$ e AUNG, NGIM e LEE $(1995)^{(10)}$ descreveram técnicas que capturam e revelam imagens tridimensionais por meio de scanner óptico e a laser, respectivamente.

MISHIMA, SUGAHARA, MORI e SAKUDA $(1996)^{(11)}$ desenvolveram digitalizador que constrói moldes tridimensionais do terço médio da face, a partir da identificação automática de pontos de referência previamente estabelecidos. Esse sistema pode ainda sobrepor e analisar simultaneamente imagens pré e pósoperatórias. 
NECHALA, MAHONEY e FARKAS (1999)(12) compararam valores de medidas da face por computador a partir de fotografia oriunda de câmera digital, e pela digitalização, por meio de scanner óptico, de filme fotográfico de $35 \mathrm{~mm}$ de câmera reflex e de fotografia por câmera Polaroid $®$, em relação a medidas obtidas por antropometria direta. Concluíram que não houve diferença estatisticamente significante entre os valores obtidos pelos quatro métodos. Os autores chegaram a essa conclusão apesar da possibilidade de poder ocorrer compressão involuntária de partes moles à mensuração direta no paciente, como por exemplo, ao medir a altura do ápice nasal ou a distância bi-alar ${ }^{(2)}$ (Figura 2).

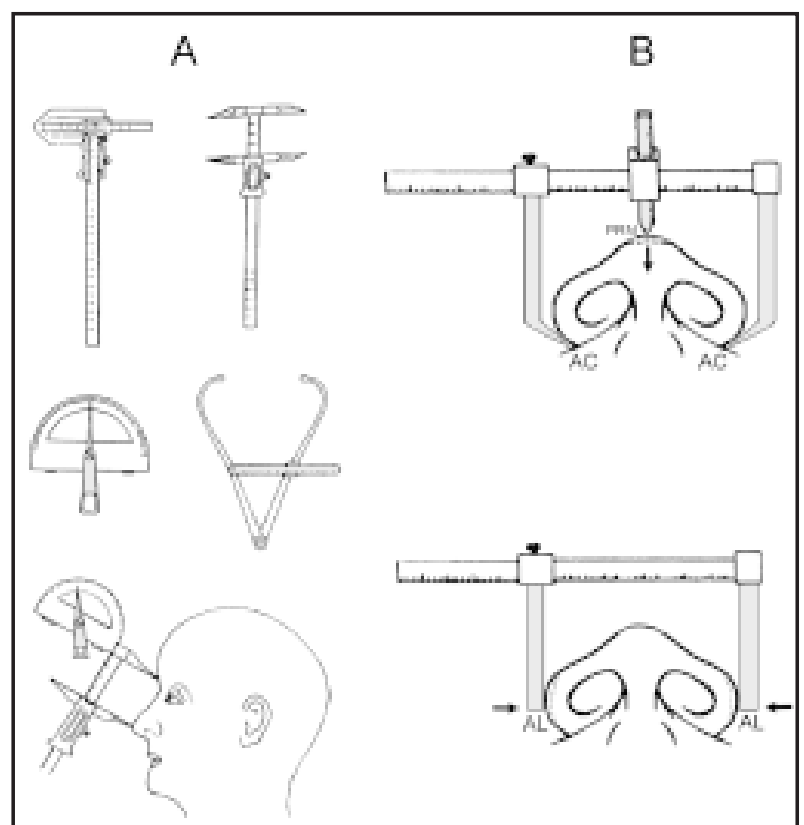

Figura 2 - Instrumentos manuais de mensuração antropométrica direta.

A - Paquímetros, transferidor e compasso graduado.

B - Mensuração da projeção do ápice nasal e mensuração da distância bi-alar (observar possíveis compressões nos locais das setas).

Seguindo a atual tendência do uso do computador, este trabalho tem por objetivo propor uma padronização fotográfica e de mensuração da parte externa do nariz, com a finalidade de poder comparar objetivamente valores de medidas entre imagens pré e pós-operatórias.

\section{MÉTODOS}

\section{Amostragem}

Foram selecionadas 11 pacientes do sexo feminino portadoras de nariz negróide, com idade variando entre 19 a 45 anos, sendo 2 de cor branca, 5 de cor parda e
4 de cor negra, provenientes do ambulatório do Setor de Rinologia da Disciplina de Cirurgia Plástica da Universidade Federal de São Paulo / Escola Paulista de Medicina.

\section{Procedimentos}

\section{1 - Padronização fotográfica}

Para avaliar a eficácia da padronização fotográfica e morfométrica comparando fotografias pré e pósoperatórias, foi utilizada máquina fotográfica tipo monoreflex com objetiva de $50 \mathrm{~mm}$ com filme colorido de $135 \mathrm{~mm}$ e ASA 100, regulada com abertura de diafragma de 5,6 e com velocidade de obturador de 1/ 60 e flash com fotômetro automático. As posições escolhidas para fotografar foram anterior, perfil ou lateral direito e basilar ou submentual.

Para padronizar as posições fotográficas em posição anterior e de perfil, demarcou-se no piso, a $70 \mathrm{~cm}$ à frente de um fundo fotográfico azul, uma linha paralela ao mesmo, e a partir do meio desta traçou-se outra perpendicular. Estas linhas foram usadas para que os pés do paciente, em posição supina, ficassem posicionados a cada lado das mesmas, com o intuito que o paciente não ficasse em alguma posição oblíqua intermediária ou flexionasse inadvertidamente o pescoço.

A fotografia anterior e de perfil do nariz incluíram toda a circunferência da cabeça até a extremidade esternal da clavícula (fúrcula esternal), e o eixo longitudinal da objetiva foi mantido perpendicular ao fundo fotográfico.

O foco da objetiva foi ajustado para uma distância de $70 \mathrm{~cm}$ do ápice nasal.

A fim de padronizar a visão basilar na mesma inclinação em relação à máquina fotográfica, os pontos antropométricos PRN (Pronasale, ou ponto mais anterior do ápice nasal) e $\mathrm{G}$ (Glabella, ou ponto anterior mais projetado da superfície óssea do osso frontal, localizado na linha mediana entre os supercílios, facilmente perceptível pela palpação) foram demarcados sobre a pele. Pediu-se que o paciente estendesse gradualmente o pescoço em sentido posterior, até que estes dois pontos ficassem alinhados em sentido caudocranial. Nesse momento foi fotografado, centralizando o ápice nasal ${ }^{(2,4)}$ (Figura 3).

A posição basilar foi fotografada com a objetiva ajustada para uma distância focal de $45 \mathrm{~cm}$ do ápice nasal.

Foram utilizados como pontos focais para facilitar o ajuste do foco da objetiva as pupilas oculares ou a transição cutâneo-mucosa dos lábios. 


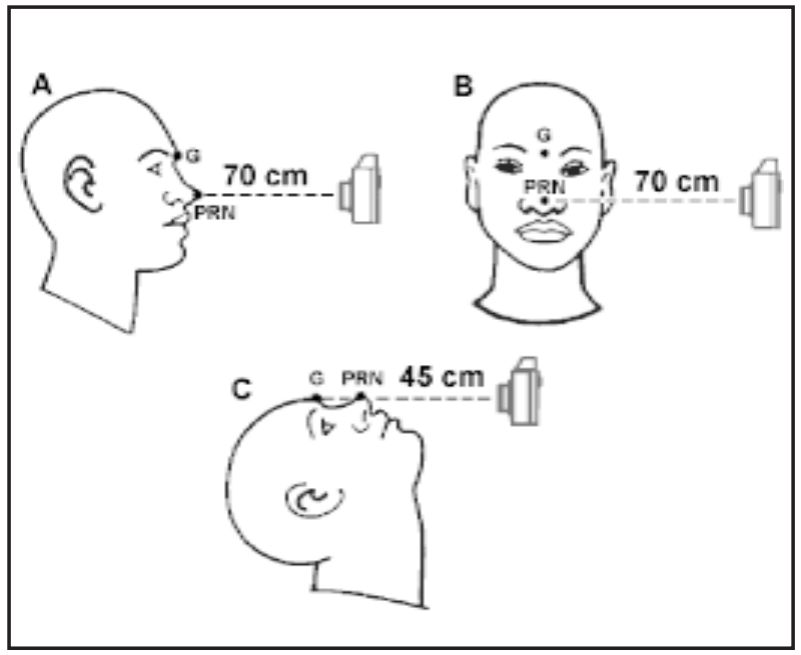

Figura 3 - Padronização fotográfica.

A - Posição anterior

B - Posição em perfil direito

C - Posição basilar

As fotografias foram ampliadas no mesmo laboratório em papel fotográfico no tamanho padrão de $10 \mathrm{x}$ $15 \mathrm{~cm}$.

Os pacientes foram fotografados antes da cirurgia e com 3 meses de pós-operatório pelo mesmo operador, equipamento e configuração, posições idênticas e em condições de luminosidade semelhantes.

As fotografias foram digitalizadas por meio de scanner de mesa óptico com 300 DPI em micro-computador pessoal com processador Pentiumâ com sistema operacional Windowsâ 98.

\section{2 - Padronização morfométrica}

Foram escolhidos pontos antropométricos, ângulos e índices relativos à parte externa do nariz, ou seja, raiz, dorso, ápice e parte móvel do septo nasal e base nasal, a qual inclui as asas nasais e narinas ${ }^{(7)}$.

Foi utilizado o programa gráfico Corel Drawâ 9.0 para realizar as mensurações.

Nas fotografias em posição anterior foi calculado o Índice Nasal Frontal ${ }^{(13)}$ (INF) modificado que é a relação entre a medida da distância entre os pontos AL (Alar, ou ponto mais lateral de cada asa nasal) e a distância ao ponto médio entre os pontos EN (Endocanthion, ou ponto correspondente à comissura palpebral medial) (Figura 4).

Nas imagens em perfil foram obtidos o Ângulo Nasolabial $^{(7)}$ (ANL), o Ângulo Nasofrontal ${ }^{(7)}$, e o Índice de Projeção do Ápice Nasal ${ }^{(14)}$ (IPAN).

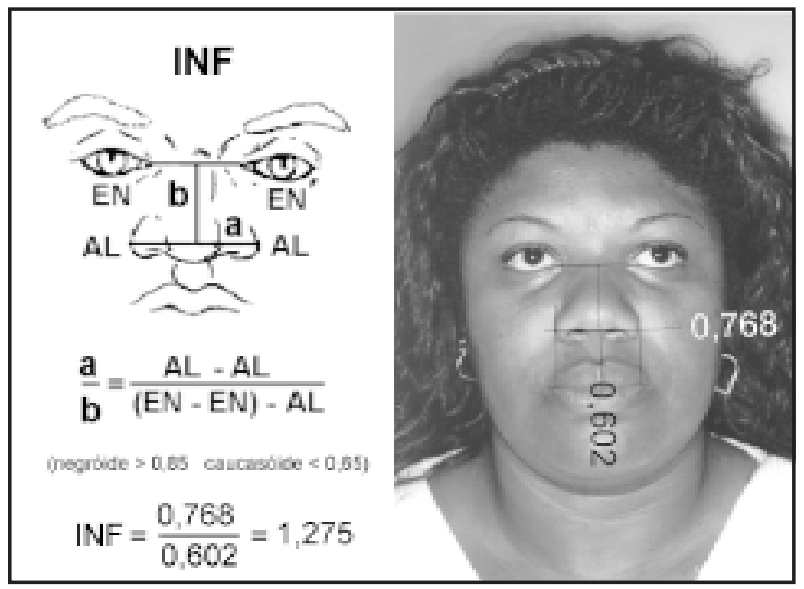

Figura 4 - Índice Nasal Frontal.

O ANL é resultante da convergência ao ponto SN (Subnasale, ou ponto de transição entre a parte móvel do septo nasal e o lábio superior) de uma linha tangencial à parte móvel do septo nasal e outra linha tangencial ao ponto UP (Upper vermilion border, ou ponto médio do filtro labial, na transição cutâneo-mucosa do lábio superior) (Figura 5).

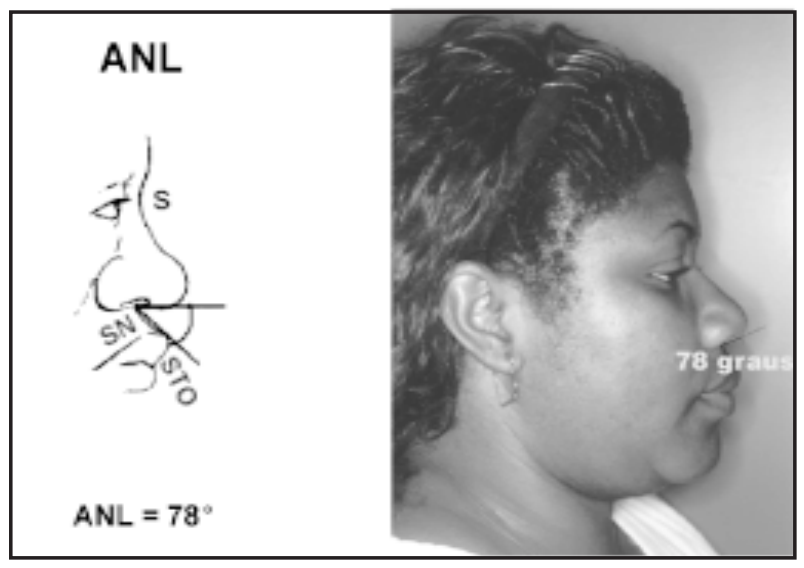

Figura 5 - Ângulo Nasolabial.

$\mathrm{O}$ ANF é resultante da convergência ao ponto $\mathrm{S}$ (Sellion, ou ponto posterior mais projetado da raiz do nariz) de uma linha tangencial ao dorso do nariz e outra linha tangencial ao ponto anterior mais projetado da raiz nasal, geralmente entre os supercílios (Figura 6).

O IPAN é a relação da medida entre o ponto $\mathrm{S}$ e o ponto UV e a medida entre o ponto PRN e o ponto C (Crumley, ou ponto de intersecção de uma linha perpendicular entre o ponto PRN e a linha S-UV) (Figura 7).

$\mathrm{Na}$ visão basilar do nariz mediu-se o Ângulo Bi$\operatorname{Alar}^{(15)}$ (ABA), o Ângulo do Eixo da Narina ${ }^{(7)}$ (AEN) direita e esquerda, o Índice de Comprimento de $\mathrm{Asa}^{(7)}$ (ICA) modificado e o Índice Nasal Basal ${ }^{(15)}$ (INB). 


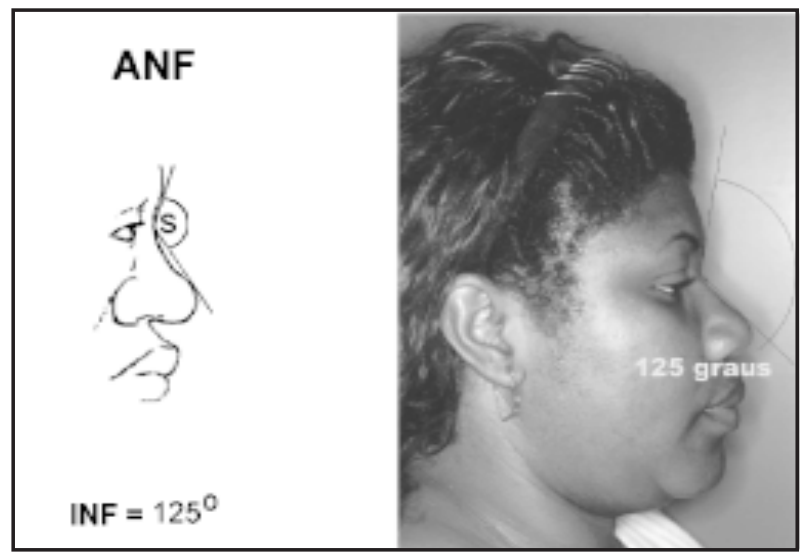

Figura 6 - Ângulo Nasofrontal.

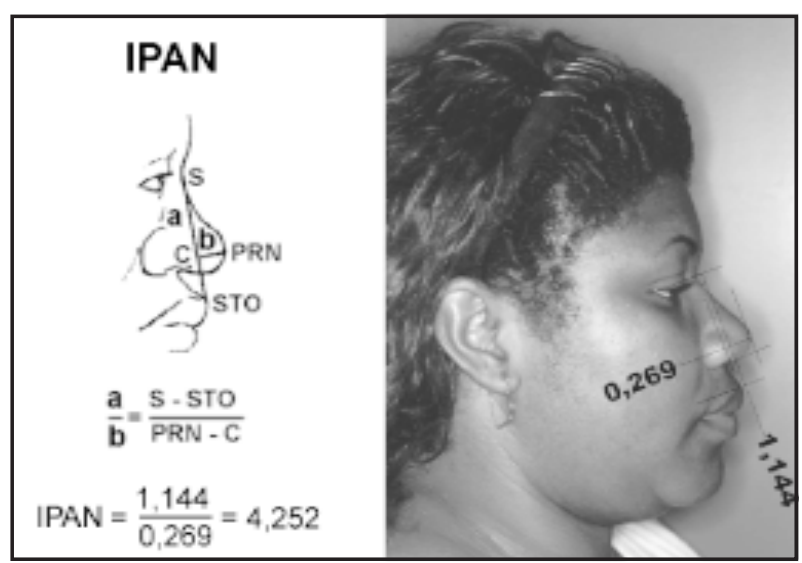

Figura 7 - Índice de Projeção do Ápice Nasal.

O ABA é formado entre duas linhas tangenciais às margens das asas nasais (Figura 8).

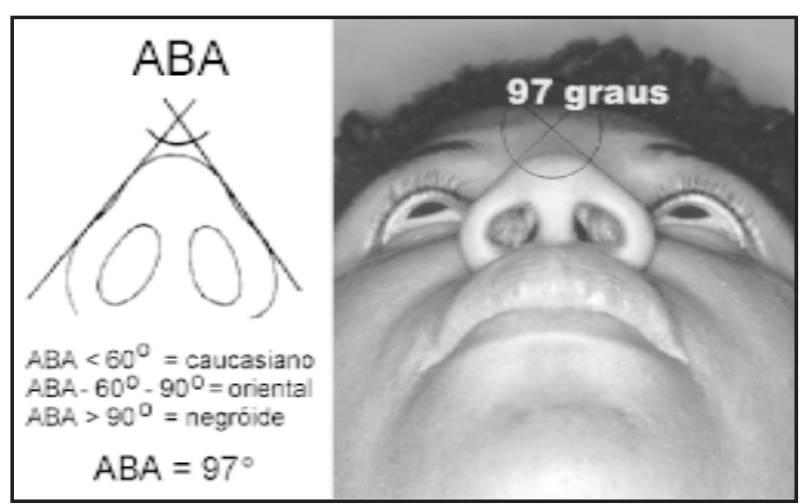

Figura 8 - Ângulo Bi-Alar.

O AEN é formado entre o eixo longitudinal de cada narina, demarcado pelos pontos C' e C" (Columela, ou ponto mais anterior e posterior da parte móvel do septo nasal, respectivamente) e uma linha horizontal que une ambos os pontos C" (Figura 9).

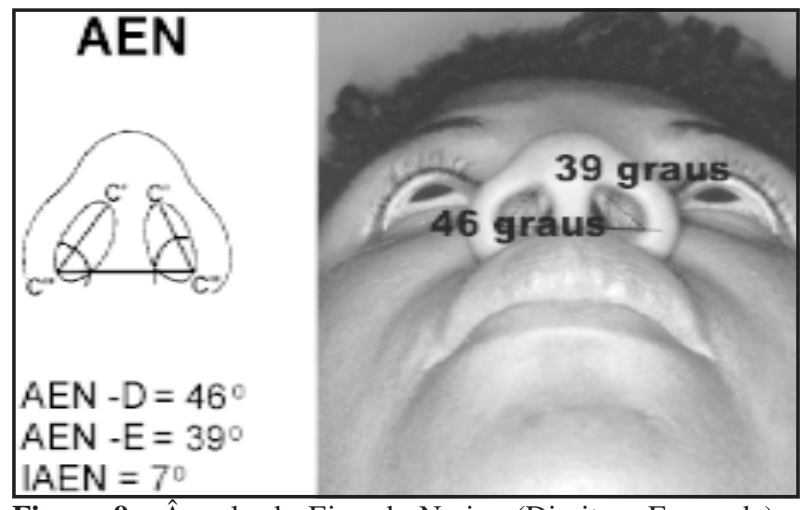

Figura 9 - Ângulo do Eixo da Narina (Direita e Esquerda) e Índice de Assimetria dos Eixos das Narinas.

A diferença de assimetria entre as narinas foi avaliada pelo cálculo da diferença de graus em valor absoluto entre o AEN direita e o AEN esquerda. Esse índice criado nesta pesquisa para quantificar as diferenças de assimetria entre o período pré e pós-operatório, foi representado pelo Índice de Assimetria entre os Eixos das Narinas (IAEN).

O ICA é a relação da medida compreendida entre ambos os pontos AL e a medida entre os pontos PRN e AC à direita (Figura 10).

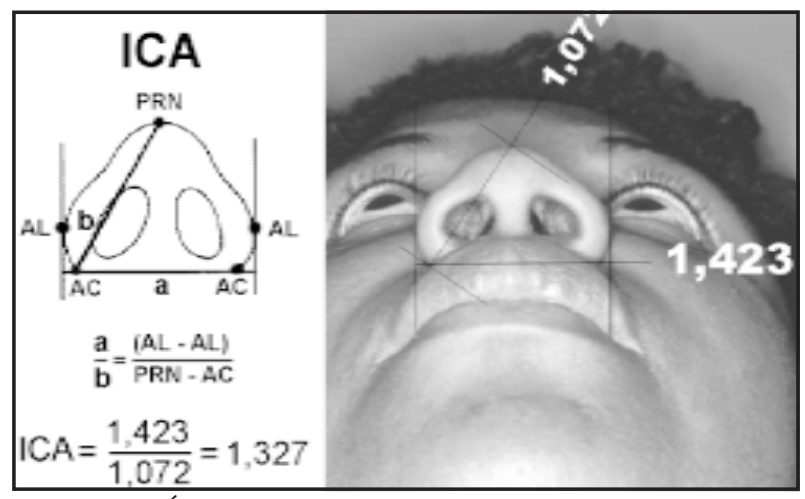

Figura 10 - Índice de Comprimento de Asa.

O INB é a relação da medida entre o ponto PRN à linha que une ambos os pontos $\mathrm{AC}$, e a medida entre o ponto mais lateral da superfície da asa nasal de cada lado (Figura 11).

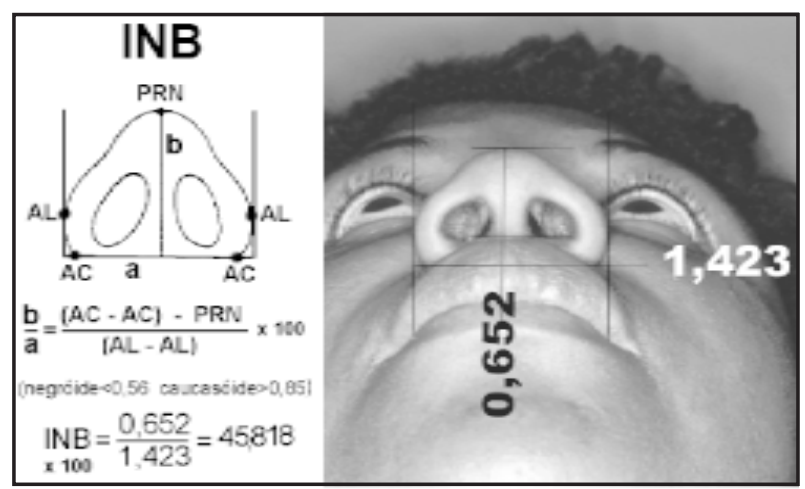

Figura 11 - Índice Nasal Basal. 
A fotogrametria das medidas lineares e angulares a partir de fotografias digitalizadas e ampliadas, foi mensurada por meio das ferramentas do software pela mesma pessoa.

\section{RESULTADOS}

$\mathrm{Na}$ técnica de padronização fotográfica proposta obteve-se imagens comparáveis quanto ao posicionamento do paciente nas posições anterior, perfil direito e basilar entre o pré e pós-operatório.

O método de mensuração mostrou-se de fácil aplicação e execução pelas ferramentas do software. Mediante o recurso do zoom, os limites do contorno do nariz para a determinação de ângulos foram nítidos (ANL, ANF, ABA E AEN), assim como foi nítida a identificação de todos os pontos antropométricos escolhidos.

O grau de precisão de ordem milesimal dos valores tornou fidedigna a comparação das fotogrametrias pré e pós-operatórias (Figuras 12 e 13).
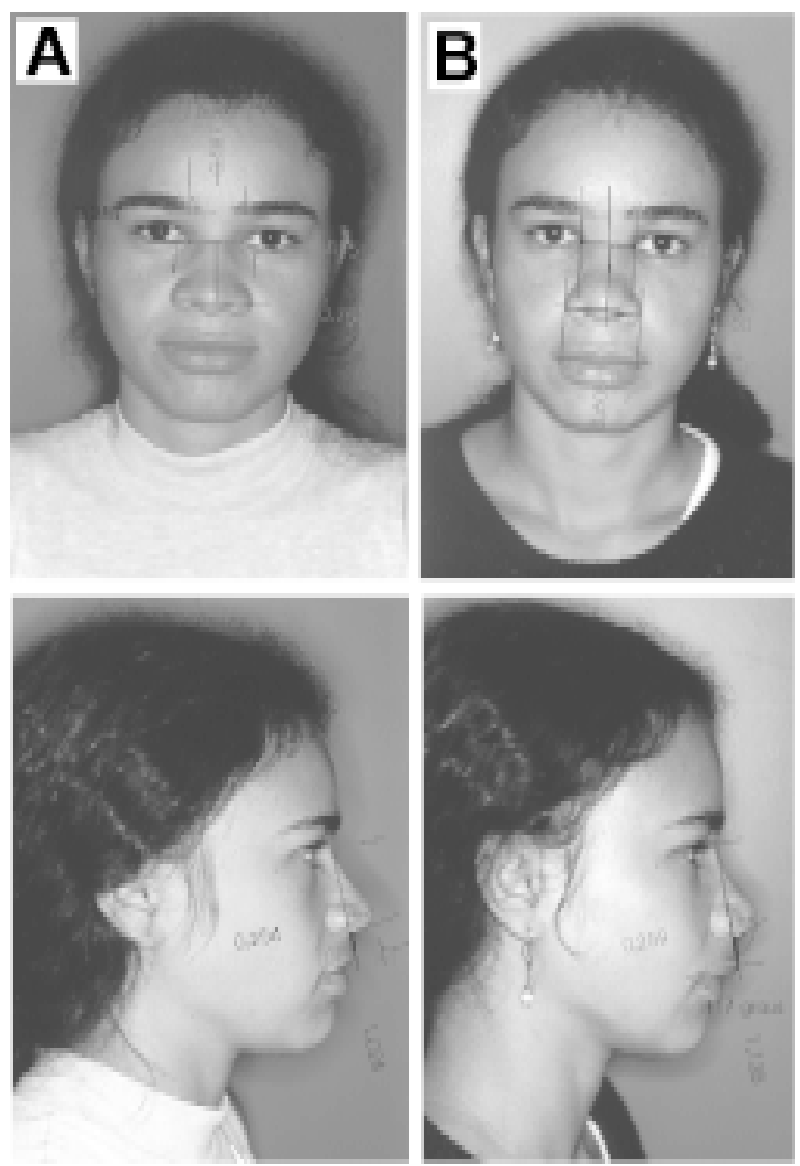

Figura 12 - Comparação de fotogrametrias nasais computadorizadas (posição anterior e de perfil direito). A - pré-operatório; B - pós-operatório.
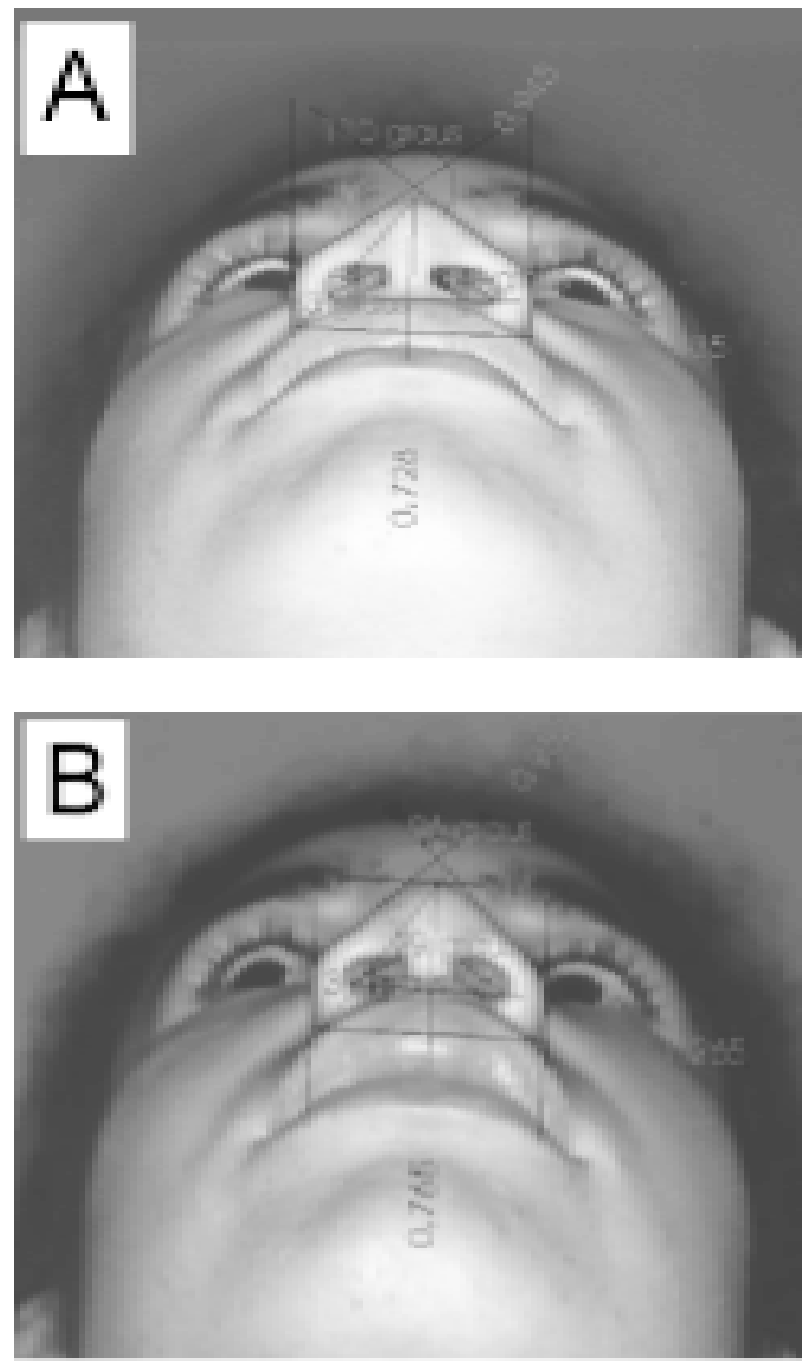

Figura 13 - Comparação de fotogrametrias nasais computadorizadas (posição basilar). A - pré-operatório; B - pósoperatório.

\section{DISCUSSÃO}

A parte mais variável do corpo é a face. O nariz, além de ocupar um lugar de destaque, é uma estrutura que varia muito na face.

Nos últimos anos a consciência de que uma avaliação apenas subjetiva de resultados cirúrgicos tornou-se insuficiente, é evidenciada na literatura com o desenvolvimento de diversos métodos de padronização fotográfica e morfométrica. Somente nessas condições, a comparação de fotografias pré e pós-operatórias podem comprovar a eficácia de determinada técnica de rinoplastia ${ }^{(3)}$.

A procura de um método de padronização que independa da capacidade artística do cirurgião veio a coincidir com o uso cada vez mais difundido do computador $^{(8)}$. 
As medidas fornecidas neste trabalho pelo software não foram submetidas à análise estatística, pois o propósito não foi discutir ou avaliar uma técnica cirúrgica, e sim apenas constatar a exequiibilidade dos métodos de padronização fotográfica e morfométrica propostos.

Foram escolhidos para demonstração pacientes portadores de nariz negróide, pelo fato deste tipo de rinoplastia ser basicamente estética, e por interessar principalmente a parte externa do nariz, objeto do nosso estudo. Nesta parte nasal está incluída a espessura da pele e do tecido fibro-adiposo, que são também mais espessos no nariz negróide.

Como alterações na parte anatômica (interna) do nariz podem repercutir na parte externa, outras mensurações nasais podem ser acrescentadas à padronização proposta, como por exemplo, o cálculo do índice da largura da parte móvel do septo nasal ${ }^{(7)}$.

Nas fotografias em posição basilar a literatura também cita como ângulo de obtenção da fotografia durante a inclinação caudo-cranial da cabeça, o encontro do ponto PRN (Pronasale) com um plano horizontal nas comissuras mediais das pálpebras ou nas extremidades mediais dos supercílios ${ }^{(4)}$. Optou-se pelo encontro do ponto PRN com o ponto G (Glabella) pelo fato deste ser ósseo e portanto estaria menos sujeito a alterações.

A validade de utilizar medidas a partir de fotografias já foi bastante questionada.

WARD (1979) ${ }^{(5)}$ pode verificar que não há diferença entre as medidas obtidas a partir de fotografias convencionais e diretamente do paciente, utilizando ângulos, índices ou mudanças de forma das narinas. A marcação de pontos antropométricos na pele antes da tomada da fotografia torna a fotogrametria mais $\operatorname{precisa}^{(6)}$.

Apesar de FARKAS e col. (1980) ${ }^{(6)}$ terem validado somente $33,3 \%$ das medidas nasais por fotogrametria, essas foram relativas apenas a medidas obtidas na visão anterior e de perfil. Segundo o próprio autor, a visão basilar, desde que devidamente padronizada, fornece dados precisos. Neste trabalho dos 9 parâmetros mensurados, 5 foram relativos à visão basilar do nariz (ABA, AEN, IAEN, ICA e INB), o que torna mais fidedignas as avaliações realizadas. Corrobora o fato desse autor também ter concluído que ângulos não são alterados na fotogrametria, assim como medidas entre dois pontos num mesmo plano sagital. Neste trabalho foram mensurados 5 ângulos [ANL, ANF, ABA, AEN e IAEN], e 2 medidas sagitais [(EN-EN)-AL no INF e (AC-AC)-PRN no INB].
NECHALA e col. (1999)(12) compararam valores de fotogrametria obtidos a partir da digitalização de fotografias de $35 \mathrm{~mm}$ e tipo Polaroid $\AA$, com a fotografia digital propriamente dita. $\mathrm{O}$ critério de validação desses valores foi a comparação com os valores obtidos a partir da antropometria direta. Nesse trabalho apenas 2 parâmetros foram relativos ao nariz (inclinação do dorso nasal em relação a uma linha vertical, e a altura nasal compreendida pela distância entre os pontos Nasion e Subnasale). Nesta pesquisa utilizou-se também a digitalização de fotografias convencionais (em papel), porém foram incluídos 9 parâmetros relativos ao nariz para serem mensurados.

As ampliações da imagem por setores pelo software permitiram uma visualização bem nítida dos limites das estruturas a serem medidas. Por isso, em relação às fotogrametrias obtidas diretamente de fotografias convencionais $^{(6,8)}$, os valores obtidos neste trabalho com fração de aproximação de ordem milesimal seriam mais precisos.

Um benefício importante deste método é diminuir ou anular a margem de erro decorrente da mensuração direta no paciente com instrumentos rígidos, como paquímetros, compassos, réguas ou transferidores, em partes do nariz mais deformáveis à compressão por esses instrumentos.

Outra vantagem decorrente da padronização fotográfica e morfométrica utilizada, é que são suficientes apenas 3 incidências fotográficas da parte externa do nariz. Na avaliação subjetiva de resultados por meio de fotografias, são utilizadas até 6 fotografias por paciente (anterior, oblíquas e de perfis direito e esquerdo e basilar).

Pelo fato das medidas obtidas serem representadas por índices ou ângulos, portanto de valor relativo, as ferramentas do software se adaptam para fazer as medições mesmo com discretas e inadvertidas inclinações da cabeça do paciente. Evitariam assim o incômodo ao paciente da utilização de aparelhos ou dispositivos que imobilizam totalmente o segmento cefálico $^{(6)}$.

Este método, além de não acarretar possível constrangimento ao paciente, torna possível ao cirurgião realizar as mensurações posteriormente em local e condições mais apropriadas para o mesmo.

A rinoplastia é uma cirurgia peculiar pelo fato do nariz possuir uma estrutura tridimensional própria e por não ser uma estrutura estática. É mantido às custas de um equilíbrio representado pelo arcabouço nasal suportando e resistindo dinamicamente à contínua contração dos músculos da face e compressão dos tecidos moles. 
No pré-operatório estas forças estão em equilíbrio. Após uma rinoplastia, a conformação final da parte externa do nariz ocorrerá quando o processo de cicatrização das estruturas anatômicas se estabilizar. Assim, por meio da fotografia é possível registrar o aspecto externo nasal em várias etapas pós-operatórias. Com esse propósito, WEBBER (1987) ${ }^{(4)}$ sugeriu fotografar o nariz após 3 meses da rinoplastia, mantendo uma freqüência trimestral até completar o $1^{\circ}$ ano, quando o ápice nasal gradualmente se tornaria mais bulboso, e no $2^{\circ}$ ano, quando lentamente começaria afinar.

Os princípios básicos da padronização fotográfica incluem a manutenção da mesma câmera fotográfica, objetiva, lentes e/ou filtros, tipo de filme, condições de iluminação, tipo e cor de fundo fotográfico, enquadramento fotográfico, ausência de maquiagem, e de preferência o mesmo fotógrafo. Apesar da avançada tecnologia das máquinas fotográficas digitais, nem todas contam com os recursos necessários que uma padronização fotográfica de rigor científico exige. Já as máquinas convencionais, preferencialmente as manuais, possuem exato ajuste da distância focal e do objeto fotografado, e do mecanismo de ajuste entre a velocidade do obturador e o controle de abertura do diafragma, o que garante uma similar exposição à luz e profundidade de campo na fotografia.

O uso misto de fotografia convencional e sua digitalização por scanner óptico como proposto propiciam uma relação custo-benefício bastante vantajosa em relação a métodos que utilizam como tecnologia digitalizadores tridimensionais e a laser ${ }^{(9,10,11)}$. Por outro lado, se uma câmera fotográfica digital possuir esses recursos operacionais com similar exatidão de ajuste das câmeras convencionais, o uso do scanner poderia ser dispensado, tornando o método fotográfico ainda mais simples, embora atualmente com um custo significativamente maior.

O manuseio operacional do programa gráfico Corel Drawâ 9.0 utilizado mostrou-se acessível a pessoas que não sejam especialistas em computação gráfica. Este programa também permite, por meio de suas ferramentas, ampliar a imagem ao tamanho real, bastando apenas colocar uma régua como referência ao lado do paciente quando for tomada a fotografia. Este recurso possibilita que a fotogrametria obtenha medidas de valor real (life-size photography), que pode ser útil para realizar estudos antropométricos.

Embora tecnicamente seja possível, não é recomendável tentar "padronizar" a tomada das fotografias mediante as ferramentas do software. Este recurso poderia acarretar distorções de resultados e não possui a confiabilidade científica de uma fotografia que realmente foi padronizada.

Finalmente, cabe lembrar que além da importância clínica, operatória e científico-acadêmica, uma documentação fotográfica padronizada também poderá possuir importante valia para o cirurgião em relação a possíveis implicações legais.

\section{CONCLUSÃO}

A padronização fotográfica proposta e de fotogrametria do nariz com o auxílio de computador a partir de fotografias comuns mostrou-se prático e eficaz para avaliar de forma objetiva imagens pré e pósoperatórias.

\section{REFERÊNCIAS}

1. Constantian MB. Interactive computer graphics: a new technology to improvise judgment in rhinoplasty. Clin Plast Surg 1987;14(4):623-30.

2. Daniel RK, Farkas LG. Rhinoplasty: image and reality. Clin Plast Surg 1988;15(1):1-10.

3. Daniel RK, Hodgson J, Lambros VS. Rhinoplasty: the light reflexes. Plast Reconstr Surg 1990;85(6):859-66.

4. Webber WB. Rhinoplasty: the importance of consistent documentation and significant long-term follow-up. Plast Reconstr Surg 1987;79(4):640-54.

5. Ward CM. An analysis, from photographs, of the results of four approaches to elongating the columela after repair of bilateral cleft lip. Plast Reconstr Surg 1979;64(1):68-76.

6. Farkas LG, Bryson W, Tech B, Klotz J. Is photogrammetry of the face reliable? Plast Reconstr Surg 1980;66(3):346-55.

7. Farkas LG, Kolar JC, Munro IR. Geography of the nose: a morphometric study. Aesthetic Plast Surg 1986;10:191-223.

8. Furnas DW. Precision nasal profileplasty with life-sized slide projections, calibrated xerograms, and intraoperative measurements. Clin Plast Surg 1987;14(4):631-7.

9. Bhatia G, Vannier MW, Smith KE, Commean BS, Riolo J, Young VL. Quantification of facial surface change using a structured light scanner. Plast Reconstr Surg 1994;94(6): 768-74.

10. Aung SC, Ngim RCK, Lee ST. Evaluation of the laser scanner as a surface measuring tool and its accuracy compared with direct facial anthropometrics measurements. Br J Plast Surg 1995;48:551-8.

11. Mishima K, Sugahara T, Mori Y, Sakuda M. Application of a new method for anthropometric analysis of the nose. Plast Reconstr Surg 1996;98(4):637-44.

12. Nechala P, Mahoney J, Farkas L. Digital two-dimensional photogrammetry: a comparision of the three techniques of obtaining digital photographs. Plast Reconstr Surg 1999;103(7):1819-25.

13. Matory WE, Falces E. Non-caucasian rhinoplasty: a 16-year experience. Plast Reconstr Surg 1986;77(2):239-51.

14. Crumley LC, Lanser M. Quantitative analyses of nasal tip projection. Laryngoscope 1988;98:202-8.

15. Watanabe K. New ideas to improve the shape of the ala of the oriental nose. Aesthetic Plast Surg 1994;18:337-44. 
Hochman B, Castilho HT, Ferreira LM. Photographic and morphometric standardization in the computerized photogrammetry of the nose. Acta Cir Bras [serial online] 2002 Jul-Aug;17(4). Available from URL: http://www.scielo.br/acb.

ABSTRACT - Objective: To develop a photographic standardization and technique of morphometric analyses of the external part of the nose to compare photographic images into an objective form of pre and post-operative. Methods: Eleven females patients were pictures bearers of negroid nose with age varying among 19 to 45 years old being 2 of white color, 5 of brown color and 4 of black color. The photographic technique was standardized in the anterior position, right profile and basal position. Pictures in paper were digitized and through common graphic software mensurations were accomplished by photogrammetry. It was used nine nasals measured, one were used in anterior position, three in right profile and five in basal position. Results: The patient's photographic positioning among the pre and post-operative were comparable. The identification of the anthropometrics points and chosen lines were clear, the obtaining of measures was of easy execution, and measures values could have approach of millesimal order, turning possible the comparison of the values. Conclusion: The procedures of photographic standardization and morphometric analyzed proposed were shown feasible, practical and necessary.

KEY WORDS - Nose. Rinoplasty. Anthropometry. Photography. Photogrammetry.

Conflito de interesse: nenhum

Endereço para correspondência:

Fonte de financiamento: nenhuma

Dr. Bernardo Hochman

Disciplina de Cirurgia Plástica/Departamento de Cirurgia

Universidade Federal de São Paulo

Rua Napoleão de Barros, 715

04024-900 São Paulo - SP

Tel: (11)5576-4118

bernardohochman@uol.com.br

Data do recebimento: 09/04/2002

Data da revisão: 14/05/2002

Data da aprovação: 04/06/2002 